Promising Practice

\title{
From Breath to Beadwork: Lessons Learned From a Trauma- Informed Yoga Series With Indigenous Adolescent Girls Under Youth Protection
}

\author{
Jessica W. G. Barudin
}

A R T I C L E I N F O

Keywords:

Indigenous youth

Adolescent girls

Trauma-informed yoga

Mindfulness

Healing

Child welfare system

Youth protection services

Residential treatment

https://doi.org/10.32799/ijih.v16i1.33220

\begin{abstract}
A B S T R A C T
This paper explores the promising practice of an emerging culturally adapted, trauma-informed yoga program for Indigenous adolescent girls. I draw from my experiential learning during a series of 12 yoga sessions over 2018 and 2019 with eight Indigenous girls (ages 13-17) from rural and remote Inuit communities in Quebec, Canada. Participants had experienced varying degrees of child maltreatment and interaction with the child welfare system, and they were all under the care of youth protection services in a residential facility. The yoga and mindfulness intervention provided weekly 60 -minute sessions in the residential unit. Yoga sessions integrated a blended model of cultural teachings, group dialogue, and trauma-informed yoga. The approach included circle sharing, cultural teachings, gentle progressions of physical postures, guided meditation, breathing techniques, centring practices, and beadwork. This promising practice explores trauma-informed yoga as a strengths-based community strategy for relational healing that promotes cultural connectedness, safety, and resilience among Indigenous adolescent girls removed from their rural and remote communities to a residential facility in an urban area. This paper outlines an introductory framework for health professionals, paraprofessionals, program administrators, and staff working with Indigenous children and youth in residential facilities. Specifically, this promising practice builds on existing findings of trauma-informed yoga with adolescents, as well as movement and centring approaches through an Indigenous lens of relational healing.
\end{abstract}

Jessica W. G. Barudin is a member of the 'Namgis First Nation living in Alert Bay, British Columbia, Canada. She is a doctoral student at Concordia University in the Department of Individualized Studies. She is also a mother of two daughters, Sundancer, and Indigenous yoga teacher with over 500 hours of teacher training experience and 8 years of experience teaching yoga to Indigenous communities. Jessica works with the First Nations Health Authority as the Traditional Wellness Specialist for Vancouver Island. Email: Jessica.barudin@fnha.ca 


\section{Glossary}

Child maltreatment: Child welfare authorities investigate child maltreatment concerns, which include allegations/suspicions of physical abuse, sexual abuse, emotional maltreatment, neglect, and exposure to intimate partner violence. ${ }^{1}$

Culturally adapted interventions: Programs that have been modified to reflect the values, traditions, beliefs, norms, practices, and worldviews of the target population. Interventions that have been culturally adapted for Indigenous Peoples are more effective than mainstream interventions.

Mindfulness: An ancient practice that engages the mind and brain to enter states of deep awareness and insight into one's life and reality. It is a tool for liberating the mind and brain from oppressive thinking, feelings, and actions (Yellow Bird, 2012).

Yoga: A system of knowledge originating from Indigenous Indian thought to support the connection to a higher power through spiritual, physical, and mental practices (i.e., body postures, breathing techniques, meditation, and philosophy).

Youth protection services: Legislated by the Youth Protection Act in Quebec, Canada, youth protection services is akin to the child welfare system or child protection services.

\section{Acknowledgements}

With deep gratitude for the participants, "my girls," who welcomed new experiences and taught me so much. Thank you to Alex Mazzerolle, creator of Girlvana Yoga teacher training, for the encouragement and foundation; Yoga Mala Foundation and Here to Be (Lululemon) for the organizational resources; Hiba Zafran (McGill University), Elizabeth Fast (Concordia University), and Louise Dessertine, for the grounding support.

\section{Relationship}

I (the author and yoga facilitator) identify as a Kwakwaka'wakw woman from the 'Namgis First Nation. This paper is written retrospectively and relating to my positionality of being an urban Indigenous person situated as a guest on Haudenosaunee territory. I was invited to teach weekly classes by the Yoga Mala Foundation, as initiated by the classroom teacher of the residential facility. I connected with the adolescent girls by relating my own challenges and experiences with my family and adolescence, drawing on difficulties with parents who struggled with substance abuse and trauma, and related how yoga and cultural connections have provided a foundation for my personal wellness journey. This paper is a reflection of offering traumainformed yoga as one resource in promoting wellness among adolescent Indigenous girls experiencing varying degrees of stress and trauma.

\footnotetext{
${ }^{1}$ Frequently, there is no allegation or suspicion that maltreatment has already occurred; however, with the presence of contextual factors (such as caregiver substance abuse or other lifestyle concerns), there is substantial risk that a child will be maltreated in the future.
} 


\section{Introduction}

Child welfare is one of the arenas where the Truth and Reconciliation Commission of Canada (TRC, 2015) has outlined five Calls to Action to respond to the overrepresentation of Indigenous youth in care. Specifically, Call to Action 4.3 calls on the Canadian government to "establish, as an important priority, a requirement that placements of [Indigenous] children into temporary and permanent care be culturally appropriate" (TRC, 2015, p. 320). There is a growing base of knowledge about traumatic experiences in the general child welfare population; however, little is known about the childhood trauma of youth placed in the most restrictive setting, residential care. Researchers have indicated a positive correlation between trauma-related symptoms and restrictiveness of placement (Collin-Vézina et al., 2011).

The current youth protection system has been imposed on Indigenous Peoples from the outside, not taking into account their cultures nor their concepts of family and wellness. Historical and contemporary child welfare policies in Canada have imposed an acculturation model of child "safety" for Indigenous children and families, which has fractured Indigenous systems of kinship and care (Blackstock, 2003). In Canada in 2016, Indigenous children under the age of 15 represented $7.7 \%$ of the child population; however, an astonishing $52.2 \%$ of children in foster care were Indigenous (Government of Canada, 2020). One in three Inuit youth in Nunavik will have come in contact with child protection services at some point in their lives (Commission des droits de la personne et des droits de la jeunesse, 2007).

Cultural connectedness serves as a protective factor against the psychosocial risks associated with trauma (Brave Heart, 1998). Healing is promoted by strengths- and culture-based approaches emphasizing youth and community empowerment that reclaim tradition, language, ceremony, and communal practices (Kirmayer et al., 2003; Reading \& Reading, 2012; Sasakamoose et al., 2016). Mindfulness and yoga practices have been recommended to assist youth in dealing with the negative effects of colonialism (Sasakamoose et al., 2016). Yoga-based practices have been used as mind-body interventions for youth in residential treatment, with promising initial reports, by integrating breathing, meditation, and rhythmic movement (Spinazzola et al., 2011). Beading is considered a traditional practice that integrates mindfulness; it provides a therapeutic and grounding process, cultivating a sense of inner peacefulness, concentration, and confidence through creation of a unique piece of work (Gray, 2017).

This paper shares reflections and lessons learned from a culturally adapted yoga series designed for adolescent Indigenous girls, and suggests ways we can provide meaningful cultural experiences as an adjunct to residential programming, treatment, and therapy for Indigenous youth under youth protection in a residential facility. The overarching themes of the yoga series included safety, sacredness, centring, (self-)compassion, connection, and sharing of our culture and language. Informed by my own cultural connections, as well as engagement from the Indigenous youth participants, the emergent class subthemes included discussion of anatomy, women's teachings about menstruation, and cultural practices, including prayer, meditation, and beading. The promising practice of trauma-informed yoga may be implemented as a communitybuilding intervention when working with Indigenous youth. 


\section{Historical Context}

For more than a century, Canadian assimilationist policies in education, child welfare, and Western health systems have intensified, creating a lasting legacy of negative impacts on the lives and well-being of Indigenous children and their families (Blackstock, 2003; Blackstock et al., 2006). Approximately 150,000 First Nations, Inuit, and Metis children were forcibly removed from their homes and communities and legally mandated to be institutionalized in the residential school system from the late 1800s to predominantly the 1950s (Barker et al., 2019; TRC, 2015). By the 1950s to 1960s, many of the residential schools had been shut down, with the last government-funded school closed in Saskatchewan in 1996 (TRC, 2015). Many children died from disease and neglect during their time in the residential schools (Sinha et al., 2011). The government policies that followed this era continued to harm Indigenous families and communities as Indigenous children were forcibly removed and sent to foster care homes or adoptive families and predominantly placed with non-Indigenous parents, a phenomenon recognized as the Sixties Scoop (Fast \& Collin-Vézina, 2010; Royal Commission on Aboriginal Peoples, 1996; Sinha et al., 2011). Children suffered relocation to unfamiliar areas far from their families, were deliberately separated from their siblings, and were forbidden to express their language, spirituality, and cultural traditions; many endured sexual, physical, psychological, and emotional abuse (Trocmé et al., 2004). Sadly, the number of Indigenous children and youth placed in the child welfare system is on the rise, and it is estimated that three times more Indigenous children are involved with Canadian child welfare systems today than at the peak of the residential school era (Blackstock, 2003; Trocmé et al., 2004).

\section{Trauma Associated With the Child Welfare System}

The severe disruption of kinship, language, identity, and spirituality associated with the child welfare system creates a legacy of trauma for Indigenous individuals, families, and communities (Barker et al., 2019; Menzies, 2008). Indigenous children in youth protection services are frequently removed and relocated to unfamiliar cities; segregated by sex in a youth facility; processed to a dormitory unit with very few personal belongings; kept for long periods without seeing their families; given extremely limited opportunities to enjoy traditional foods; and in some extreme cases, are punished for speaking their native language (Lowrie, 2018). This is history repeating itself.

The attention on individual trauma (i.e., post-traumatic stress disorder) is misguided and does not sufficiently reflect Indigenous experiences of trauma, nor does it consider the complex and compounded interactions of Adverse Childhood Experiences (ACEs), historical traumas, and current experiences of trauma such as witnessing or experiencing intrafamilial abuse, suicide of family members, and daily racism and discrimination (Evans-Campbell, 2008; Warner et al., 2014). Researchers indicate that youth may become retraumatized and suffer exacerbated trauma symptoms when they are suddenly and unexpectedly removed from their homes, relocated to residential settings, and forced to adapt to unfamiliar environments and people (Spinazzola et al., 2011). 
There are numerous mental, physical, emotional, and spiritual impacts of complex trauma. Research with youth in residential facilities has found that responses to trauma often manifest in issues with attachment, self-monitoring, behavioural control, establishing limits and healthy boundaries, poorer cognition, negative self-concept, and high-risk behaviours (e.g., violence toward self and others and substance abuse [Spinazzola et al., 2011]). Although Indigenous youth come to the attention of youth protection services for various reasons, the assumed high prevalence of trauma histories calls for trauma-informed interventions and wellness activities that support youth in cultivating a sense of safety in their bodies and regulatory skills to manage stressful emotions and situations (Abrams, 2008; Spinazzola et al., 2011).

\section{Trauma-Informed Yoga}

The practices of yoga and unifying mind and body have been utilized as a way of reducing stress and dis-ease for thousands of years; yoga has the distinction of being one of the oldest spiritual practices in the world (Nolan, 2016). Yoga is a spiritual system of knowledge rooted in Indigenous Indian knowledge, and the word has been interpreted over the centuries to mean "to tie the strands of the mind together" and "to be one with the Divine" (Desikachar, 1995). Yoga in North America is widely understood and accepted as a physical practice of postures, breathing, and relaxation, joining mind, body, and spirit for the purpose of health (Abrams, 2008; Iyengar, 1966). Although yoga has many benefits, typical yoga practices in the West (i.e., in studio settings) may present challenges or be triggering for people who have experienced trauma. Trauma researchers highlight the importance of trauma-informed yoga over typical forms of Westernized yoga found in yoga studios because the latter emphasizes posture attainment, with certain yoga poses reminding survivors of their abuse and vulnerabilities associated with it (Emerson \& Hopper, 2011). It may be potentially triggering with hands-on adjustments and use of commanding language which does not align with trauma-informed principles (Emerson, 2015).

Yamasaki (2019) defines trauma-informed yoga as an empowering yoga practice that prioritizes the lived experience and healing of a trauma survivor. It offers body-based tools (gentle movement and breathing techniques) to support people who have experienced trauma in cultivating a connection and relationship with their bodies, thus easing symptoms and trauma responses (Spinazzola et al., 2011). Developed by the Justice Resource Institute, traumasensitive yoga is another approach that utilizes yoga to support individuals who have experienced psychological trauma (Emerson, 2015). Both trauma-sensitive and trauma-informed yoga provide a somatic approach to establishing and enhancing self-regulatory capacity in interoception (inward awareness) and skills for shifting and balancing physiological arousal (van der Kolk, 2015).

\section{Approach}

In 2018-2019, I collaborated with a youth protection residential unit in Quebec, Canada, and led 12 weekly yoga sessions each lasting 60 minutes offered within the residential facility. 
This program was guided by the engagement and input of the non-Indigenous classroom teacher and eight participants who were adolescent Indigenous girls (ages 13-17 years) from rural and remote Inuit communities. I am an Indigenous yoga teacher with extensive teacher training and trauma-informed training background. Yoga was also carefully approached as a spiritual practice originating from Indian culture and intelligence-I dedicated care and attention to informing the youth participants about the roots of yoga.

\section{Trauma-Informed Yoga Approach}

The core principles of trauma-informed yoga include safety, trust, choice, empowerment, collaboration, and cultural competence (Yamasaki, 2019). I used my experience, intuition, and the trauma-informed yoga approaches and principles outlined by van der Kolk (2015) and trauma-sensitive yoga as outlined by Emerson (2015). The somatically based, nonverbal practice promoted self-regulation by modelling movements; using slow progressions and invitational, empowerment-based language; integrating choices; and providing a variety of options, as well as through careful selection of physical poses (Emerson \& Hopper, 2011; Warner et al., 2014). Other key aspects included maintaining a supportive and nonjudgmental presence and creating a "healing container" (Barudin \& Zafran, 2019). In terms of qualifications and credentials, a foundation of yoga teacher training (i.e., 200 hours) is essential, with additional certification in trauma-informed yoga training. I recommend a yoga teacher with cultural safety training and a grounding in cultural humility as essential for leading any such practice.

\section{Structure of Yoga Sessions}

Each yoga session included the following components:

1. Circle check-in and sharing, introduction of theme

2. Movement practice or yoga sequence (series of postures, breathing, and relaxation practices)
a. Centring practice
b. Warm-up
c. Targeted warm-up
d. General practice
e. Cool-down
f. Final relaxation or meditation

3. Closing circle, sharing food or journaling, and check-out

4. Clean-up, putting mats, blocks, and blankets away

Following circle check-in with a guided question, the movement practice began with a seated centring focus with an optional opportunity to practise spiritual cleansing or "smudging" with sacred plant medicines including sage, sweetgrass, and cedar. I began with a cultural teaching from my medicine bundle ${ }^{1}$ and/or a story during class check-in through circle sharing

\footnotetext{
${ }^{1}$ Includes a physical and spiritual "container" of sacred items, including teachings, songs, instruments, plant medicines, seeds, and cultural teachings. Medicine bundle cultural teachings include: eagle feather teachings; sacred
} 
using an eagle feather. During the warm-up, I created safety by using a gentle, nonjudgmental tone. Invitational language emphasized phrases such as "I invite you to listen to your body" and "everything is optional" in order to create a choice-based environment where participants are in control and choose to participate in ways that feel comfortable. I often encouraged participants to "notice," "observe," "feel," and "explore" connection to their physical body and their breath.

A blend of yoga styles was offered throughout the series, including hatha yoga, introductory vinyasa ${ }^{1}$ yoga, and a few restorative yoga poses, ${ }^{2}$ according to the energy level of the participants. Sessions explored a variety of physical poses (asanas) that matched the abilities and physical needs of the participants. Poses explored a variety of positions in seated, standing, standing balance, supine, and prone positions. Participants also explored a number of breathing techniques (pranayama), hand gestures (mudras), visualization, and restorative (deep rest) postures. The final resting pose in yoga (savasana) invites participants to lie down on their mat with their eyes closed. This can be triggering for some trauma survivors, and youth participants may disengage or distract other participants during this time, so options were given of seated meditation or legs up the wall with eyes open or closed. Due to the unique nature of trauma, physical adjustments or touching participants was not part of the series to avoid any discomfort or triggers. We used journaling and dialogue throughout the series to provide another way to integrate teachings and themes in the yoga sessions. An example of the yoga session and structure is outlined in Table 1.

\section{Table 1}

Sample Yoga Session Sequence and Structure

Theme: Adapting to changes and grounding ourselves (calming anxiety)

\begin{tabular}{|l|l|c|}
\hline Component & Pose/Technique & $\begin{array}{c}\text { Time } \\
\text { (minutes) }\end{array}$ \\
\hline Set up (pre-session) & Prepare mats in circle or two rows facing each other & 5 \\
\hline Opening & $\begin{array}{l}\text { Circle and check-in } \\
\text { "Describe your mood as the weather" } \\
\text { Cultural teaching about prayer } \\
\text { (Option to smudge) }\end{array}$ & 5 \\
\hline Centring & $\begin{array}{l}\text { Meditation / Alternate nostril breathing } \\
\text { Child's pose }\end{array}$ & 5 \\
\hline Warm-up & $\begin{array}{l}\text { Table top } \\
\text { Cat/cow } \\
\text { Downward dog } \\
\text { Forward fold }\end{array}$ & 5 \\
\hline
\end{tabular}

plant medicine teachings (i.e., cedar, sage, tobacco, sweetgrass); song teachings; circle teachings; hand drum teachings; women's teachings; water teachings; and fire teachings.

${ }^{1}$ A dynamic and sometimes more vigorous series of yoga postures that links movement with breath.

${ }^{2}$ Aims for fewer poses with a focus on deep, relaxed breathing and longer or passive holding of stretches or poses. 


\section{Table 1 con't}

\begin{tabular}{|l|l|c|}
\hline Component & Pose/Technique & $\begin{array}{c}\text { Time } \\
\text { (minutes) }\end{array}$ \\
\hline Targeted warm-up & $\begin{array}{l}\text { Sun salutation (2-3 times) } \\
\text { Chair pose } \\
\text { Plank pose } \\
\text { Cobra pose }\end{array}$ & 5 \\
\hline General practice & $\begin{array}{l}\text { Downward dog } \\
\text { Low lunge } \\
\text { Warrior I } \\
\text { Standing knee to chest } \\
\text { Tree pose } \\
\text { Forward fold } \\
\text { (Repeat on opposite side) }\end{array}$ & 10 \\
\hline Cool-down/ closing & $\begin{array}{l}\text { Bridge pose } \\
\text { Reclined twist } \\
\text { Thread the needle } \\
\text { Final relaxation pose (savasana) }\end{array}$ & \\
\hline $\begin{array}{l}\text { Closing circle/journaling } \\
\text { check-out }\end{array}$ & $\begin{array}{l}\text { Circle sharing with food } \\
\text { Clean up mats, props }\end{array}$ & 10 \\
\hline Debrief (post-session) & Debrief with teacher or unit lead & 10 \\
\hline End & & 5 \\
\hline
\end{tabular}

\section{Cultural Adaptations and Considerations}

Land-based healing and spirituality are well known by Indigenous people as "good medicine" to recalibrate the body, mind, and spirit (Simpson, 2014; Tuck et al., 2014); however, many Indigenous people encounter barriers in accessing land-based and traditional practices. The youth described in this intervention did not have access to land-based healing, ceremonies, or traditional practices and rarely received traditional foods. I shared cultural teachings from my Nation, connections to ceremonial circles (i.e., Anishinaabe, Haudenosaunee), and personal reflections, weaving them throughout each session to provide a sense of trust, safety, and authentic experience while bringing a land-based approach to the residential facility. I also offered some teachings from my medicine bundle. See Table 2 for an overview of yoga poses that I matched with goals and cultural teachings. 


\section{Table 2}

Culturally Adapted, Trauma-Informed Yoga Goals

\begin{tabular}{|c|c|c|c|}
\hline $\begin{array}{l}\text { Emotional } \\
\text { challenge }\end{array}$ & Cultural teaching & $\begin{array}{l}\text { Posture/technique (Sanskrit } \\
\text { name) }\end{array}$ & Goal/outcome \\
\hline $\begin{array}{l}\text { Off-balance, } \\
\text { conflicted }\end{array}$ & $\begin{array}{l}\text { - Cedar teachings- } \\
\text { balance of mind-body- } \\
\text { spirit } \\
\text { - Smelling cedar } \\
\text { leaves, drinking cedar } \\
\text { tea, purifying with } \\
\text { cedar }\end{array}$ & $\begin{array}{l}\text { - Mountain pose (Tadasana) } \\
\text { - Tree pose (Vrksasana) } \\
\text { - Eagle pose (Garudasana) } \\
\text { - Half moon pose (Ardha } \\
\text { chandrasana) }\end{array}$ & $\begin{array}{l}\text { Feeling a sense of } \\
\text { stability, accepting } \\
\text { changes }\end{array}$ \\
\hline $\begin{array}{l}\text { Anger, rage, } \\
\text { frustration }\end{array}$ & $\begin{array}{l}\text { - Compassion-eagle } \\
\text { feather teachings } \\
\text { - Circle teachings }\end{array}$ & $\begin{array}{l}\text { - Eagle mudra (Garuda } \\
\text { mudra) } \\
\text { - Ocean breath } \\
\text { - Heart openers, e.g. Camel } \\
\text { pose (Ustrasana) } \\
\text { - Writing letter to self }\end{array}$ & $\begin{array}{l}\text { Releasing anger, } \\
\text { building relationships } \\
\text { with self and others }\end{array}$ \\
\hline $\begin{array}{l}\text { Anxiety, tension, } \\
\text { panic }\end{array}$ & $\begin{array}{l}\text { Air/wind-cleansing } \\
\text { qualities }\end{array}$ & $\begin{array}{l}\text { - Alternate nostril breathing } \\
\text { (Nadi Shodana) } \\
\text { - Neck rolls } \\
\text { - Modified sun salutations } \\
\text { - Reclined knee(s) to chest } \\
\text { (Pavanamuktasana) } \\
\text { - Reclined pigeon pose } \\
\text { (Supta kapotasana) }\end{array}$ & $\begin{array}{l}\text { Calming nervous } \\
\text { system, sensing body, } \\
\text { feeling grounded }\end{array}$ \\
\hline $\begin{array}{l}\text { Emotionally numb, } \\
\text { dissociated }\end{array}$ & $\begin{array}{l}\text { Earth-Earth as our } \\
\text { mother; feeling } \\
\text { grounded and } \\
\text { connected to the land }\end{array}$ & $\begin{array}{l}\text { - Visualization of the land } \\
\text { - Child's pose (Balasana) } \\
\text { - Plank pose (Phalakasana) } \\
\text { - Low lunge variations } \\
\text { (Anjaneyasana) } \\
\text { - Mountain pose (Tadasana) }\end{array}$ & $\begin{array}{l}\text { Centring, grounding, } \\
\text { connecting to a safe } \\
\text { space or memory, } \\
\text { awareness of body }\end{array}$ \\
\hline $\begin{array}{l}\text { Low energy } \\
\text { (hypoarousal) }\end{array}$ & $\begin{array}{l}\text { Fire teachings- } \\
\text { healing powers of fire } \\
\text { (transformation) and } \\
\text { destructive powers of } \\
\text { fire }\end{array}$ & $\begin{array}{l}\text { - Breath of fire breathing } \\
\text { - Forward fold (Uttanasana) } \\
\text { - Downward dog (Adho } \\
\text { mukha svanasana) } \\
\text { - Core exercises }\end{array}$ & $\begin{array}{l}\text { Decreasing } \\
\text { hypoarousal, } \\
\text { increasing arousal }\end{array}$ \\
\hline Distracted & $\begin{array}{l}\text { Peacefulness and } \\
\text { contemplation }\end{array}$ & $\begin{array}{l}\text { - Ratio breathing ( } 3: 3 \text { or } 4: 4) \\
\text { - Sun salutation } \\
\text { - Rhythmic movements } \\
\text { - Fountain of youth breathing }\end{array}$ & $\begin{array}{l}\text { Feeling a state of } \\
\text { flow and connection, } \\
\text { sensing body }\end{array}$ \\
\hline
\end{tabular}


Table 2 con't

\begin{tabular}{|c|c|c|c|}
\hline $\begin{array}{l}\text { Emotional } \\
\text { challenge }\end{array}$ & Cultural teaching & $\begin{array}{l}\text { Posture/technique (Sanskrit } \\
\text { name) }\end{array}$ & Goal/outcome \\
\hline Isolated & $\begin{array}{l}\text { - Prayer-connecting } \\
\text { with spirit, Creator, } \\
\text { ancestors } \\
\text { - Sweetgrass teachings }\end{array}$ & $\begin{array}{l}\text { - Meditation with hand on } \\
\text { heart } \\
\text { - Self-massage } \\
\text { - Journaling } \\
\text { - Supported child's pose } \\
\text { (Balasana) } \\
\text { - Supported bridge (Setu } \\
\text { Bandha Sarvangasana) }\end{array}$ & $\begin{array}{l}\text { Connecting, feeling } \\
\text { supported }\end{array}$ \\
\hline $\begin{array}{l}\text { Disempowered, } \\
\text { helpless }\end{array}$ & $\begin{array}{l}\text { Women's teachings- } \\
\text { menstrual cycle, power } \\
\text { of menstruating time as } \\
\text { ceremony }\end{array}$ & $\begin{array}{l}\text { - Warrior I/II/III } \\
\text { (Virabhdrasana) } \\
\text { - Chair pose (Utkatasana) } \\
\text { - Yogic squat (Malasana) } \\
\text { - Plank (Phalakasana) }\end{array}$ & $\begin{array}{l}\text { Empowered, feeling } \\
\text { sacred }\end{array}$ \\
\hline Sad, numb, upset & $\begin{array}{l}\text { Water teachings- } \\
\text { healing power of tears, } \\
\text { praying over water, } \\
\text { sacred waters within } \\
\text { women's bodies }\end{array}$ & $\begin{array}{l}\text { - Belly breathing (hand on } \\
\text { belly and heart) } \\
\text { - Lion's breath } \\
\text { - Butterfly pose (Baddha } \\
\text { Konasana) } \\
\text { - Happy baby* }\end{array}$ & $\begin{array}{l}\text { Cultivating } \\
\text { resilience, } \\
\text { unfreezing; adapting }\end{array}$ \\
\hline $\begin{array}{l}\text { Emotionally } \\
\text { overwhelmed }\end{array}$ & $\begin{array}{l}\text { - Smudging-sage } \\
\text { teachings } \\
\text { - Moon teachings }\end{array}$ & $\begin{array}{l}\text { - Shoulder rolls } \\
\text { - Alternate nostril breathing } \\
\text { - Restorative heart opener } \\
\text { - Legs up the wall (Viparita } \\
\text { Karani) } \\
\text { - Final relaxation pose } \\
\text { (Savasana)* }\end{array}$ & $\begin{array}{l}\text { Releasing heavy } \\
\text { emotions, feeling } \\
\text { present }\end{array}$ \\
\hline
\end{tabular}

Yoga sessions evolved organically to include beadwork (Figure 1). As Gray (2017, p. 24) put it, "There is ritual to beading that binds the community together." The youth had regularly complimented my beaded earring collection and showed a keen interest to learn how to make their own. With support from their classroom teacher, a collection of seed beads, thread, needles, hooks, wax, and scissors were purchased. The participants provided their colour preferences and had the freedom to choose their favourite colours and styles to create earrings to keep or gift to others. The beading practice followed the opening circle check-in, spiritual cleansing, centring practice, and a short meditation to remind participants to bring "good, calm energy" into their work.

\section{Figure 1}

Breath to Beadwork: Earrings Made by Two Adolescent Girls Participating in the Weekly Yoga Sessions 


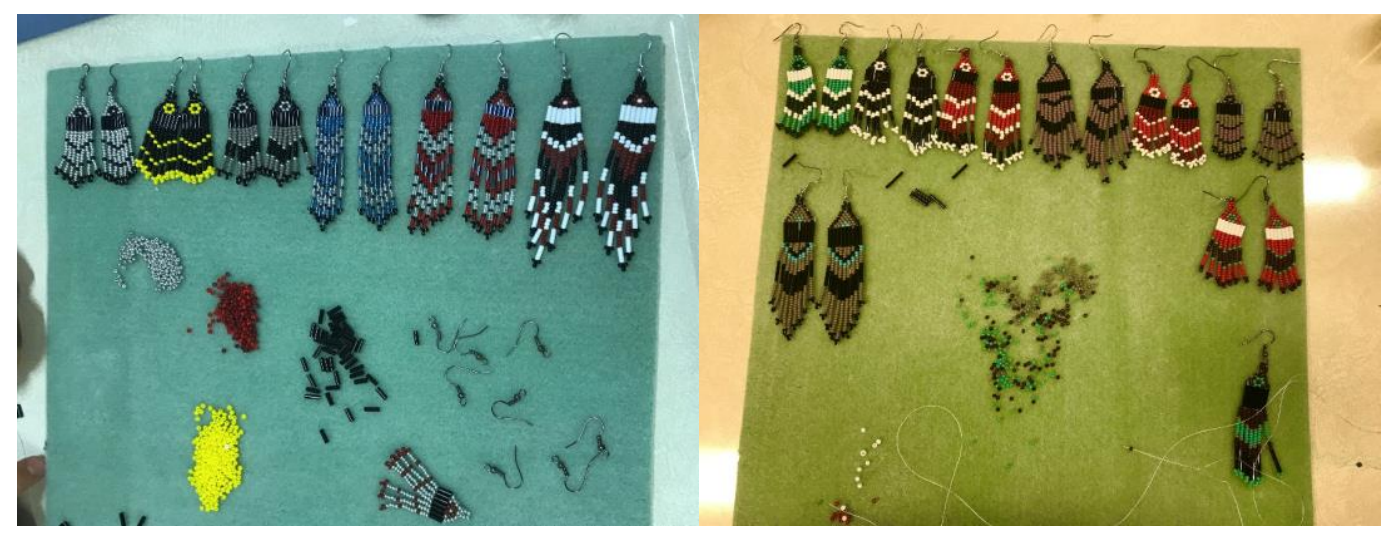

\section{Reflections}

The yoga series provided a social activity to promote a sense of connection to self and each other. The authentic connection shared between the girls, myself as the facilitator, and their classroom teacher made this series unique.

\section{Lessons Learned}

Safety and creating a sacred space were pillars of each session. My goal as a yoga teacher was to create a "healing container" and provide a space where the girls could express themselves. This hinged on my ability to establish an emotional connection and relationship with each girl. Adaptability each week to each moment of the class was important. I constantly observed their comfort, energy level, and engagement throughout the sessions. Our yoga session provided a safe space for the participants to sleep and rest, especially when there were sleep disturbances during the night in the unit, which occurred regularly. I noticed there were dramatic shifts in comfort and engagement depending on who was in the room, including a decrease in perceived ease when some security guards and staff members were present, particularly males.

The progression to beadwork emerged from a natural orienting toward a cultural practice, which required (a) trust, (b) desire to engage in this practice, and (c) an ability to concentrate, choose, commit, and create. Beading involves tremendous patience, focused intention, concentration, and creativity - it became a progression from our seated meditations to a creative, moving meditation. Although beading brought us together in a shared practice, the beading needles and scissors were strictly accounted for by security and the teacher to maintain safety in the unit and prevent any self-harm injuries. The risk of self-harm and suicide was a high concern within the residential facility. I had to be adaptive in offering modifications for one participant who was healing from a severe, self-inflicted wrist laceration and had physical difficulty with some of the postures.

Dialogue in circle sharing at times was brief, which I observed may have been due to language barriers, as each participant predominantly spoke their traditional language and English as a second language. Furthermore, expressing oneself verbally seemed to be less culturally relevant for this group of youth. We explored journaling in a few sessions; however, I also 
reflected that the overall English literacy of the group may have been a barrier, and in the future I would integrate more art and craft practices in lieu of writing.

\section{Elements for Success}

I invited and encouraged the girls to share any teachings, traditions, language, and medicines from their Nations. They were very receptive when learning about other Nations' customs, foods, and ceremonies. We often shared food at the end of practice (e.g., maple water, chocolate, fruits, and nuts) during the circle check-out to allow for more opportunities for participants to express themselves.

I spent a considerable amount of time curating playlists featuring Indigenous artists for the background music to our practice sessions. I chose artists who composed songs in their traditional languages. Later in the series, I asked participants to choose the artists for the yoga and beadwork playlists, which promoted a sense of ownership and improved participation.

The variety of different yoga styles, poses, and breathing exercises enhanced the girls' interest throughout the session. Progressions of movements and yoga poses were intentionally slow, aligned with trauma-sensitive yoga guidelines (Emerson, 2015). Rhythmic movements (such as modified sun salutations) were observed as more engaging for the girls, including largerange-of-motion movements linked with breath. As we moved to the cooling and restful close of our practice, my approach was to provide several options that felt restful, comfortable, and enjoyable to absorb the practice and stay there with eyes open or closed for 3-5 minutes.

\section{Relational Healing}

The sacred space and the healing container became easier to "hold" with the girls as the practices continued and our trust was established. With our cultural sharing of medicines, experiences in our communities, and stories about our families, it created a safe space for the girls to cry, release anger, and laugh. I shared about being vulnerable and opened up about my own lived experiences as a young woman and as a mother. They listened more intently to stories, especially when I would share about my family. This was something they were curious about and it helped us connect more deeply.

I learned that my own self-care practices were tremendously important in order to continue the weekly sessions. Creating time and space before and after these yoga sessions was critical for my emotional processing and reflexivity as a facilitator. Having a pre-session dialogue and debrief with the classroom teacher guided any changes to a planned session and provided valuable feedback and mutual support. One thing that was evident in my experience was that what happened in the "community," in this case the residential unit, happened to all of us. This was painfully evident when one of the girls was abruptly transferred to another facility. One way I used our opening check in time together was sitting in circle and preparing notes to send to her.

There were times when I experienced vicarious trauma, deep sadness, and helplessness from sessions with the girls. Having support from colleagues, friends, and my therapist helped me recognize effective ways to unpack those experiences, lean into emotions when necessary, 
and disengage through the recommended practice of "having tea and staring out of a window" following the weekly sessions.

The future direction of this novel approach will be explored throughout my doctoral project, titled Re-Connecting Through Women's Teachings, Language and Movement: Culturally Responsive Yoga for First Nations Women and Girls. This research project will explore identitybuilding, healing, and decolonizing practices of yoga through the embodiment of traditional language and values. Specifically, my goal is to co-create an empowering space for Kwakwaka'wakw women and girls to see/experience themselves, their value, and their culture and language represented in an accessible and safe practice.

\section{Limitations}

This paper is written retrospectively and as a reflection to inform a promising practice. This series was not initiated as, or intended to be, a research study. Therefore, there was no formality with surveying or interviewing participants, nor were baseline measurements or assessments completed before or after. ${ }^{1}$ There were several changes to the number of adolescent girls participating in the series. For instance, during the series, some of the adolescents in the program either returned home, were allocated to "out of home" arrangements, or were transferred or aged out of the residential program. Although there was some consistency with several participants over the duration of the series, we did not have a set cohort throughout all 12 sessions. Finally, as my role was a volunteer yoga teacher, I had limited agency to provide input or recommendations to the residential facility for trauma-informed programming.

\section{Discussion}

The goal of this yoga series was to provide a safe space for participants to explore presence, breath, body connection, and self-soothing practices while integrating cultural teachings with respect to the participants' respective heritage. This series provided a structured, safe environment for the participants. The Reflections section discussed the importance of creating safety and trust among Indigenous adolescent girls in the child welfare system as a precursor to and ongoing touchstone of a healing practice.

This is a novel intervention with practical applications that may be shared in other contexts, including youth aging out of the child welfare system, Indigenous people involved with the criminal justice system, sex workers, and Indigenous people who have endured domestic, physical, or sexual violence. This type of intervention may be adapted to help inform and connect facility administrators, staff, educators, social workers, and mental health support teams in providing culturally adapted interventions. When staff participate, they have unique privileges to learn about the girls' culture and resilience as well as experience relational healing. Additionally, the advantage for the staff participating in wellness and cultural activities with

\footnotetext{
${ }^{1}$ Since this was not a formal research project, I have not indicated the participants' Nation(s) in order to ensure confidentiality.
} 
Indigenous youth is that these activities provide an opportunity for "seeing" and "hearing" youth, and so may also help eliminate or challenge certain pre-existing prejudices and stereotypes. Given the history of incarceration and forced removal of Indigenous individuals that continues to this day, interventions like this need to be done in collaboration with Indigenous communities, healers, wellness practitioners, and artists.

It is critical that any yoga program launched in similar settings ensure thorough screening and background checks of potential yoga teachers and youth facilitators. For instance, through the supporting organizations, I completed a criminal record check to work with vulnerable youth and had completed trauma-informed yoga teacher training. There are increasing numbers of Indigenous people pursuing yoga teacher training; however, in the event there is not an Indigenous yoga teacher available to guide such programming, it is essential that any nonIndigenous yoga teacher has a foundation of cultural safety training and an approach rooted in cultural humility and respect. When institutional resources allow, training staff in traumainformed yoga and facilitation would be highly beneficial to support relationship building, selfregulation, and wellness strategy promotion among the youth.

A residential facility is a "last resort" option for children and youth; there is little focus on healing (similar to prison systems). The institutional and systemic repercussions of youth protection services have negative effects on both the staff and residents. Creative, culturally informed practices, involving both staff and residents, are a cost-effective intervention that has the potential to improve relationships, mitigate attachment issues, and promote a sense of community within the institution.

\section{Conclusion}

There is a paucity of research and clear understanding about how embodied and relational healing practices using Indigenous wellness frameworks can be adapted for vulnerable populations, including Indigenous adolescents who have been maltreated and/or are under youth protection. This promising practice is not going to solve any of the systemic and institutional issues in the youth protection system. However, it provides a means to empower youth and may be considered as an adjunct to therapy and programming for multidisciplinary support for the youth.

Indigenous, provincial, and federal governments are obligated to ensure the protection of children and youth, and to promote their well-being. As stated, the TRC (2015) calls for all child welfare organizations and institutions to provide adequate resources to enable Indigenous communities and child welfare organizations to keep Indigenous families together where it is safe to do so, and to keep children in culturally appropriate environments, regardless of where they reside. Given the low cost, minimal negative impact, adaptability, and accessibility of using trauma-informed yoga and mindfulness approaches in residential facilities, there is merit in further exploration of yoga, meditation, and embodied practices in resilience programming for maltreated, at-risk youth. 


\section{References}

Abrams, H. (2008). Towards an understanding of mindful practices with children and adolescents in residential treatment. Residential Treatment for Children \& Youth, 24(12), 93-109. https://doi.org/10.1080/08865710802147497

Barker, B., Sedgemore, K., Tourangeau, M., Lagimodiere, L., Milloy, J., Dong, H., Hayashi, K., Shoveller, J., Kerr, T., \& DeBeck, K. (2019). Intergenerational trauma: The relationship between residential schools and the child welfare system among young people who use drugs in Vancouver, Canada. Journal of Adolescent Health, 65(2), 248-254. https://doi.org/10.1016/j.jadohealth.2019.01.022

Barudin, J., \& Zafran, H. (2019). Introduction to trauma-informed rehabilitation with Indigenous clients. Physiotherapy Practice, 9(5), 18-21. https://www.researchgate.net/publication/339513551_Introduction_to_traumainformed_rehabilitation_with_Indigenous_communities

Blackstock, C. (2003). First Nations child and family services: Restoring peace and harmony in First Nations communities. In K. Kufeldt \& B. McKenzie (Eds.), Child welfare: Connecting research, policy, and practice (pp. 331-342). Wilfrid Laurier University Press.

Blackstock, C., Cross, T., George, J., Brown, I., \& Formsma, J. (2006). Reconciliation in child welfare: Touchstones of hope for Indigenous children, youth, and families. First Nations Child \& Family Caring Society of Canada / National Indian Child Welfare Association. https://fncaringsociety.com/sites/default/files/Touchstones_of_Hope.pdf

Brave Heart, M. Y. H. (1998). The return to the sacred path: Healing the historical trauma and historical unresolved grief response among the Lakota through a psychoeducational group intervention. Smith College Studies in Social Work, 68(3), 287-305. https://doi.org/10.1080/00377319809517532

Collin-Vézina, D., Coleman, K., Milne, L., Sell, J., \& Daigneault, I. (2011). Trauma experiences, maltreatment-related impairments, and resilience among child welfare youth in residential care. International Journal of Mental Health and Addiction, 9(5), 577-589. https://doi.org/10.1007/s11469-011-9323-8

Commission des droits de la personne et des droits de la jeunesse. (2007). Nunavik: Report, conclusions of the investigation and recommendations. http://www.deslibris.ca/ID/208084

Desikachar, T. K. V. (1999). The heart of yoga: Developing a personal practice. Simon and Schuster.

Emerson, D. (2015). Trauma-sensitive yoga in therapy: Bringing the body into treatment. WW Norton \& Company. Emerson, D., \& Hopper, E. (2012). Overcoming trauma through yoga: Reclaiming your body. North Atlantic Books.

Evans-Campbell, T. (2008). Historical trauma in American Indian/Native Alaska communities: A multilevel framework for exploring impacts on individuals, families, and communities. Journal of Interpersonal Violence, 23(3), 316-338. https://doi.org/10.1177/0886260507312290 
Fast, E., \& Collin-Vézina, D. (2010). Historical trauma, race-based trauma, and resilience of Indigenous Peoples: A literature review. First Peoples Child \& Family Review, 5(1), 126-136. https://doi.org/10.7202/1069069ar

Government of Canada. (2020). Reducing the number of Indigenous children in care. https://www.sac-isc.gc.ca/eng/1541187352297/1541187392851

Gray, M. J. (2017). Beads: Symbols of Indigenous Cultural Resilience and Value [Doctoral dissertation, University of Toronto]. TSpace. https://tspace.library.utoronto.ca/handle/1807/82564

Houser, M. E. (2015). A mixed methods evaluation of the effectiveness of a group yoga intervention as an adjunctive trauma therapy for adolescent girls [Doctoral dissertation, University of Denver]. Digital Commons @ DU. https://digitalcommons.du.edu/etd/1063

Iyengar, B. K. S. (1966). Light on yoga. Schocken Books.

Kirmayer, L., Simpson, C., \& Cargo, M. (2003). Healing traditions: Culture, community and mental health promotion with Canadian Aboriginal Peoples. Australasian Psychiatry, 11(1_suppl), S15-S23. https://doi.org/10.1046/j.1038-5282.2003.02010.x

Lowrie, M. (2018, December 21). Human rights body probing reports Inuit kids punished for speaking Inuktitut. CTV News. https://montreal.ctvnews.ca/human-rights-body-probingreports-inuit-kids-punished-for-speaking-inuktitut-1.4227966

https://fncaringsociety.com/sites/default/files/First-Nations-Fact-Sheet-Revised-Jan2011.pdf

Menzies, P. (2008). Developing an Aboriginal healing model for intergenerational trauma. International Journal of Health Promotion and Education, 46(2), 41-48. https://doi.org/10.1080/14635240.2008.10708128

Nolan, C. R. (2016). Bending without breaking: A narrative review of trauma-sensitive yoga for women with PTSD. Complementary Therapies in Clinical Practice, 24, 32-40. https://doi.org/10.1016/j.ctcp.2016.05.006

Reading, C., \& Reading, J. (2012). Promising practices in Aboriginal community health promotion interventions. In I. Rootman, S. Dupéré, A. Pederson, \& M. O’Neill (Eds.), Health promotion in Canada: Critical perspectives on practice (3rd ed., pp. 160-170). Canadian Scholars' Press.

Royal Commission on Aboriginal Peoples. (1996). Report of the Royal Commission on Aboriginal Peoples. Library and Archives Canada. https://www.baclac.gc.ca/eng/discover/aboriginal-heritage/royal-commission-aboriginalpeoples/Pages/final-report.aspx

Sasakamoose, J., Scerbe, A., Wenaus, I., \& Scandrett, A. (2016). First Nation and Métis youth perspectives of health: An Indigenous qualitative inquiry. Qualitative Inquiry, 22(8), 636-650. https://doi.org/10.1177/1077800416629695

Simpson, L. B. (2014). Land as pedagogy: Nishnaabeg intelligence and rebellious transformation. Decolonization: Indigeneity, Education \& Society, 3(3), 1-25.

Sinha, V., Trocmé, N., Fallon, B., MacLaurin, B., Fast, E., Thomas Prokop, S., Petti, T., Kozlowski, A., Black, T., Weightman, P., Bennett, M., Formsma, J., Brascoupe, P., 
O’Brien, S., Flette, E., Gray, R., Lucas, L., Hoey, S., Levi, J., ... Richard, K. (2011). Kiskisik Awasisak: Remember the children: Understanding the overrepresentation of First Nations children in the child welfare system. Assembly of First Nations. https://cwrp.ca/sites/default/files/publications/en/FNCIS-2008_FinalReport.pdf

Spinazzola, J., Rhodes, A. M., Emerson, D., Earle, E., \& Monroe, K. (2011). Application of yoga in residential treatment of traumatized youth. Journal of the American Psychiatric Nurses Association, 17(6), 431-444. https://doi.org/10.1177/1078390311418359

Trocmé, N., Knoke, D., \& Blackstock, C. (2004). Pathways to the overrepresentation of Aboriginal children in Canada's child welfare system. Social Service Review, 78(4), 577600. https://doi.org/10.1086/424545

Truth and Reconciliation Commission of Canada. (2015). Honouring the truth, reconciling for the future: Summary of the final report of the Truth and Reconciliation Commission of Canada. http://www.trc.ca/assets/pdf/Honouring_the_Truth_Reconciling_for_the_Future_July_23 2015.pdf

Tuck, E., McKenzie, M., \& McCoy, K. (2014). Land education: Indigenous, post-colonial, and decolonizing perspectives on place and environmental education research. Environmental Education Research, 20(1), 1-23. https://doi.org/10.1080/13504622.2013.877708

van der Kolk, B. (2015). The body keeps the score: Brain, mind, and body in the healing of trauma. Penguin Books.

Warner, E., Spinazzola, J., Westcott, A., Gunn, C., \& Hodgdon, H. (2014). The body can change the score: Empirical support for somatic regulation in the treatment of traumatized adolescents. Journal of Child \& Adolescent Trauma, 7(4), 237-246. https://doi.org/10.1007/s40653-014-0030-z

Yamasaki, Z. (2019). Transcending sexual trauma through yoga [Teacher training manual for trauma-informed yoga].

Yellow Bird, M. (2012). Neurodecolonization using mindfulness practices to delete the neural networks of colonialism. In Waziyatawin \& M. Yellow Bird (Eds.), For Indigenous minds only: A decolonization handbook (pp. 57-83). The School for Advanced Research Press. 